\title{
Impact of the regional climate and substance properties on the fate and atmospheric long-range transport of persistent organic pollutants - examples of DDT and $\gamma-\mathrm{HCH}$
}

\author{
V. S. Semeena ${ }^{1,2}$, J. Feichter ${ }^{1}$, and G. Lammel ${ }^{1}$ \\ ${ }^{1}$ Max Planck Institute for Meteorology, Centre for Marine and Atmospheric Sciences (ZMAW), Hamburg, Germany \\ ${ }^{2}$ Meteorological Institute, University of Hamburg, Centre for Marine and Atmospheric Sciences (ZMAW), Hamburg, \\ Germany
}

Received: 18 October 2005 - Published in Atmos. Chem. Phys. Discuss.: 6 December 2005

Revised: 21 February 2006 - Accepted: 6 March 2006 - Published: 21 April 2006

\begin{abstract}
A global multicompartment model which is based on a 3-D atmospheric general circulation model (ECHAM5) coupled to 2-D soil, vegetation and sea surface mixed layer reservoirs, is used to simulate the atmospheric transports and total environmental fate of dichlorodiphenyltrichloroethane (DDT) and $\gamma$-hexachlorocyclohexane $(\gamma-\mathrm{HCH}$, lindane). Emissions into the model world reflect the substance's agricultural usage in 1980 and 1990 and same amounts in sequential years are applied. Four scenarios of DDT usage and atmospheric decay and one scenario of $\gamma-\mathrm{HCH}$ are studied over a decade.

The global environment is predicted to be contaminated by the substances within ca. 2 a (years). DDT reaches quasisteady state within 3-4a in the atmosphere and vegetation compartments, ca. $6 \mathrm{a}$ in the sea surface mixed layer and near to or slightly more than $10 \mathrm{a}$ in soil. Lindane reaches quasisteady state in the atmosphere and vegetation within $2 \mathrm{a}$, in soils within 8 years and near to or slightly more than $10 \mathrm{a}$ and in the sea surface mixed layer. The substances' differences in environmental behaviour translate into differences in the compartmental distribution and total environmental residence time, $\tau_{\text {overall }}$. $\tau_{\text {overall }} \approx 0.8$ a for $\gamma$-HCH's and $\approx 1.0$ 1.3 a for the various DDT scenarios. Both substances' distributions are predicted to migrate in northerly direction, $5-12^{\circ}$ for DDT and $6.7^{\circ}$ for lindane between the first and the tenth year in the environment. Cycling in various receptor regions is a complex superposition of influences of regional climate, advection, and the substance's physico-chemical properties. As a result of these processes the model simulations show that remote boreal regions are not necessarily less contaminated than tropical receptor regions. Although the atmosphere accounts for only $1 \%$ of the total contaminant bur-
\end{abstract}

Correspondence to: G. Lammel

(lammel@dkrz.de) den, transport and transformation in the atmosphere is key for the distribution in other compartments. Hence, besides the physico-chemical properties of pollutants the location of application (entry) affects persistence and accumulation emphasizing the need for georeferenced exposure models.

\section{Introduction}

The presence of pesticides in the atmosphere was first reported in the 1960s, when chlorinated products have been used widely. Persistent pesticides like DDT and $\gamma-\mathrm{HCH}$ undergo long-range transport and were found in the polar regions at remarkably high concentration levels (Bidleman et al., 1990; Egan et al., 1995; Harner et al., 1999; Macdonald et al., 2000; Pacyna, 1995). Since then, techniques for collection and analysis of atmospheric samples of organic contaminants have been developed and improved and more evidence was accumulated (UNEP, 2003; AMAP, 2003).

The cycling of the semivolatile organic compounds (SOCs) in the environment is the result of the combined action of many processes the molecules undergo: mode, temporal and spatial patterns of release or application (in agriculture), uptake by leaves through stomatae or cuticulae, partitioning in the soil multi-phase system, washout to ground water, degradation or volatilisation from leaves and soil, transport by winds, partitioning to atmospheric particles and cloud droplets, chemical degradation by radicals, dry and wet deposition of the gaseous molecules or of the particulate or droplet carrier, again partitioning in the soil or, aquatic multi-phase system, vertical transport to ocean or freshwater sediments and horizontally by ocean currents and rivers, biotic or abiotic chemical degradation, uptake by organisms of the lowest trophic level or grazers, eventually accumulation

Published by Copernicus GmbH on behalf of the European Geosciences Union. 
along food chains or re-volatilisation from ground to air. The substance properties are important for all of these processes with the exception of transport with winds or water currents (e.g. Schwarzenbach et al., 1993). The atmosphere acts as both carrier and sink medium for many organic compounds. However, the physico-chemical properties of many substances are not well known (e.g. Klecka et al., 2000; Pontolillo and Eganhouse, 2001).

Substances which resist degrading processes in the environment pose a hazard to the ecosystems and, through accumulation along food chains, also for human health. If the substances are mobile and subject to long-range transport an even larger exposure of the environment and ecosystems results. Therefore, the substance's long-range transport potential and its resistance to degradation in the total (multicompartment) environment, the so-called total environmental residence time or overall persistence, are considered as key substance characteristics in the context of environmental exposure and risk assessments (Frische et al., 1982; Vallack et al., 1998; Klecka et al., 2000; Steinhäuser, 2001; AMAP, 2004). These characteristics are dependent on time and location of substance entry into the environment (Leip and Lammel, 2004). They are in use in legally binding international conventions (POP conventions) as criteria to identify problematic substances (UNECE, 1998; UNEP-CEG, 1999). In general, for the study of trace substances' environmental cycling on larger than local scales, modelling is complementary to observational approaches and indispensable for budgeting. While experiments in a closed multicompartment environment (e.g. an ecotron) can address persistence, only modelling can study the combined action of multicompartmental chemistry and transport. Furthermore, while monitoring (at remote locations) can identify those substances which undergo long-range transport, only modelling has the potential to quantify this characteristics.

Box models and box models combined to zonally averaged 1-2-D models have been in use to understand the behaviour of these substances in the multi-media environment (Wania and Mackay, 1995, 1999). Limitations exist in predicting long-range transport with these models, because the environment is not geo-referenced in the model world. Transports (winds, ocean currents) are represented by mean largescale eddy coefficients, and the temporal variability of meteorological conditions is not reflected. Multicompartment models based on regional and global atmospheric models are under development since a few years and have been used to study the behaviour of selected POPs up to decades on the regional scale (Hansen et al., 2004; Malanichev et al., 2004) and up to a few years on the global scale (Koziol and Pudykiewicz, 2001; Lammel et al., 2001; Leip and Lammel, 2004). The model used here is a general circulation model (GCM) while the other aforementioned models are Eulerian atmospheric transport and chemistry models (CTMs). CTMs use assimilated meteorological fields to drive the transports, while GCMs generate their own meteorology. Though sim- ulating the transports closer to the real, historic weather, the physics is not totally consistent in CTMs, while it is totally consistent in GCMs. Furthermore, GCMs describe sub-grid scale transport, removal by precipitation, types of hydrometeors and many more features in a consistent way. The representation of SOCs cycling in models differs with respect to the number and detail of the description of environmental compartments covered, their dimensionality, and the process resolution. The number of compartments covered is 3-4 for most models. The atmospheric compartment is most comprehensively described in GCMs.

The aim of the present study is to shed some light on the significance of global usage pattern and atmospheric transport for the cycling and contamination pathways of two substances with different properties, $p, p^{\prime}$-DDT and $\gamma$-HCH and to address for the first time the decadal temporal scale with a 3-D dynamic multicompartment model. The selected substances are subject to regulation under the POP conventions and conventions for the protection of the seas.

\section{Model description}

The model is based on an atmosphere general circulation model (AGCM) which had been shown to be well suited to represent the large scale atmospheric dynamics and, the hydrological and aerosol cycle, ECHAM (Roeckner et al., 2006; Hagemann et al., 2006; Stier et al., 2005). The most recent version, ECHAM5, is used. A chemistry scheme (Feichter et al., 1996) and a dynamic aerosol model (HAM, Stier et al., 2005) are included. In HAM, aerosols are represented by seven log-normal modes, four soluble and three insoluble. Mass of the chemical components and number concentrations are predicted by the model. HAM takes into account the aerosol components sulphate, black carbon, organic carbon (primary and secondary), mineral dust and seasalt. As the mass fraction of SOCs in total suspended particulate matter (TSP) is negligible, we neglect the mass added to the aerosols, but use them as a carrier of the mass. As soon as the substance is released into the model atmosphere, partitioning between gas and particulate matter phase takes place and both phases are transported independently.

By addition of 2-D ground compartments, a multicompartment model is complemented (first described in Lammel et al., 2001). Vegetation and soil are distributed georeferenced as single layer boxes. A well mixed surface layer ocean with locally and seasonally varying depth, taken from a 3-D ocean general circulation model (Drijfhout et al., 1996), is included. The substances are treated similar upon deposition from gas or particulate phase.

Not all the processes of multicompartmental cycling are captured by our model: sediments, ocean transport and the inner volume of biota are not represented in the model. 


\section{Parameterizations of substance cycling processes}

\subsection{Atmosphere}

The atmosphere is a three phase system (gas, particles, cloudwater), with the mass exchange of trace substances between them being controlled by instantaneous equilibria (Henry equilibrium for air-water, equilibrium air-organic phase as represented by air-octanol).

\subsubsection{Gas-particle partitioning in air}

In this study we estimate the ratio between gas-phase and atmospheric particulate matter, $\theta$, by either absorption into organic matter empirically based on the octanol-air partition coefficient, $K_{o a}$ (Finizio et al., 1997), or adsorption onto aerosol surfaces based on an empirical relationship between vapour pressure and aerosol surface (Junge, 1977; Pankow, 1987).

The Junge-Pankow equation has the form:

$\theta=\frac{c \times \phi}{c \times \phi+P}$

$\phi$ is the surface area of particles per unit volume of air $\left(\mathrm{cm}^{-1}\right), P$ is the vapour pressure $(\mathrm{Pa})$ and the parameter $c$ (17.2 Pa cm; Junge, 1977) is related to the heat of desorption from the particle surface, the heat of vapourisation of the compound, and the density of adsorption sites on the aerosol (Boethling and Mackay, 2000). The $K_{\text {oa }}$ absorption model was found to describe adequately the partitioning of a number of organochlorine compounds (polychlorinated biphenyls and pesticides, DDT, besides others Finizio et al., 1997; Harner and Bidleman, 1998). Accordingly, for both DDT and $\gamma-\mathrm{HCH}$ we use:

$\log K_{p}=0.55 \log K_{\text {oa }}-8.23$,

with $K_{p}$ is the particle-gas partition coefficient in $\mathrm{m}^{3} \mu \mathrm{g}^{-1}$ related to $\theta$ as:

$\theta=\frac{1}{\frac{1}{K_{p} \times c_{\mathrm{TSP}}}+1}$,

with $c_{\text {TSP }}$ being the concentration of total suspended particulate matter in $\mu \mathrm{g} \mathrm{m}^{-3}$.

For the substances under study, a value of $K_{o a}$ is available for $T=298 \mathrm{~K}$ but not as a function of temperature (Harner and Bidleman, 1998). At present, no adequate data basis exists to describe the temperature dependent sorption process on atmospheric particulate matter nor even the isothermal sorption process. Neglecting temperature dependence would be significantly misleading, however. E.g. $\theta=0.0016$ would be predicted for DDT for all temperatures while $\theta=0.1-0.3$ was observed in the ambient atmosphere (Kaupp and Umlauf, 1992). In lack of measured data we assume that the temperature dependence of gas-particle partitioning, $\theta(\mathrm{T})$, behaves similar as for polycyclic aromatic hydrocarbons
(PAHs). For various PAHs, $\theta$ doubles per $4.9 \mathrm{~K}$ decrease in temperature (mean, individual species show similar behaviour, Pankow, 1991). The assumption of an analogy to PAHs is supported as these, similar to the organochlorines, partition due to both adsorption and absorption processes. Thus $\theta$ is defined as:

$\theta=\left(\frac{1}{\frac{1}{K_{p} \times c_{\mathrm{tsp}}}+1}\right) \times 2^{\frac{(298-\mathrm{T})}{4.9}}$,

where $T$ is the atmospheric temperature in $\mathrm{K}$.

\subsubsection{Degradation in air}

Chemical degradation in the atmosphere is controlled by reaction with the hydroxyl radical during daytime and with the nitrate radical during nighttime. These radicals are fed to the model prescribed as a function of latitude, longitude, month and time of day (Roelofs et al., 1997). SOC's day time atmospheric decay reaction rate is given as

$\frac{\partial c}{\partial t}=k_{\mathrm{OH}} \times c_{\mathrm{OH}} \times c_{\mathrm{SOC}}$

and the night time decay due to reaction with the nitrate radical is given as

$\frac{\partial c}{\partial t}=k_{\mathrm{NO}_{3}} \times c_{\mathrm{NO}_{3}} \times c_{\mathrm{SOC}}$

where temperature dependent rate constants, $k_{\mathrm{OH}}$ and $k_{\mathrm{NO}_{3}}$ are formulated following van't Hoff.

\subsection{Soil}

In the model, a single layer soil model is used, i.e. the top soil layer.

\subsubsection{Volatilisation from soil}

Volatilisation occurs from the pore space upon partitioning in the three-phase system of pore space, soil water and soil organic phase (Smit et al., 1997). The mathematical formulation of the phase partitioning is given as:

$c_{\text {aqueous }}=K_{\frac{l}{g}} \times c_{\text {vapour }}$

with: $c_{\text {aqueous }}=$ concentration of pesticide in soil water $\left(\mathrm{kg} \mathrm{m}^{-3}\right)$,

$c_{\text {vapour }}=$ concentration of the pesticide in the gas phase $\left(\mathrm{kg} \mathrm{m}^{-3}\right)$, and

$K_{\frac{l}{g}}=$ water-gas partitioning coefficient (dimensionless Henry coefficient). The temperature dependent vapour pressure (Clausius-Clapeyron equation) is used to determine $K_{\frac{l}{g}}$. Soil hydrology is described by a bucket model (Roeckner et al., 1996). 
The concentration of the pesticide in the soil system $\left(\mathrm{kg} \mathrm{m}^{-3}\right)$ is described by:

$c_{\text {soil }}=Q \times c_{\text {vapour }}$

with the capacity factor $Q$ as:

$Q=\theta_{\text {gas }}+\theta_{\text {liquid }} K_{\frac{l}{g}}+\rho_{\text {soil }} K_{\frac{l}{g}} K_{\frac{s}{\tau}}$,

with $K_{T}=$ solid-liquid partitioning coefficient $\left(\mathrm{kg} \mathrm{m}^{-3}\right)$, $\theta_{\text {gas }}=$ volume fraction of gas (dimensionless),

$\theta_{\text {liquid }}=$ volume fraction of moisture (dimensionless),

$\rho_{\text {soil }}=$ dry bulk density of the soil $\left(\mathrm{kg} \mathrm{m}^{-3}\right)$.

$K_{\frac{s}{l}}$ can be calculated as:

$K_{s}=K_{o m} \times c_{o m}$,

where $K_{o m}$ is the sorption coefficient and $c_{\text {om }}$ is the organic matter content of the soil. These data are provided for 9 classes (0-200 $\mathrm{kg} \mathrm{m}^{-3}$; Batjes, 1996).

The dimensionless fraction of the pesticide in the gas phase is then calculated as

$F_{g}=\frac{\theta_{\text {gas }}}{Q}$.

The volatilisation rate is a function of the pore space gaseous concentration of the substance and derived from cumulative volatilisation $(\mathrm{CV})$ experiments. $\mathrm{CV}$ of applied dosage has been empirically described based on field and greenhouse experiments with numerous pesticides (Smit et al., 1997). For normal to moist field conditions CV is given as:

$\mathrm{CV}=71.9+11.6 \log \left(100 F_{g}\right)$

with $\mathrm{F}_{\mathrm{g}} \leq 16.33 \times 10^{-9}$.

For dry field conditions, the following relation is considered:

$\mathrm{CV}_{\text {dry }}=42.3+9.0 \log \left(100 \mathrm{~F}_{\mathrm{g}}\right)$,

with $\mathrm{F}_{\mathrm{g}} \geq 1.9955 \times 10^{-7}$.

\subsubsection{Degradation in soil}

An overall first order biological and chemical degradation in soil is considered and assumed to double per $10 \mathrm{~K}$ temperature increase to account for observations of the temperature dependence of biological activity (and according to recommendations, ECB, 1996). The decay coefficient for soil is calculated as:

$k_{\text {soil }(\mathrm{T})}=k_{\text {soil }} \times 2^{\frac{(T-298)}{10}}$.

\subsection{Vegetation}

In the model, vegetation is represented as a seasonal varying distribution of the leaf area index (LAI). Application, deposition and volatilisation is parameterized proportional to the LAI, but no mass exchange takes place into the vegetation compartment. We adopt the same $k_{\text {soil }}$ as degradation rate for vegetation in lack of better knowledge. For a large number of compounds it was found, however, that the vapour pressure alone can describe the cumulative volatilisation with sufficient accuracy. The empirical relation between cumulative volatilisation $(\mathrm{CV})$ and vapour pressure $(p)$ can be written as

$\log \mathrm{CV}=a+b \log p$,

with $a=1.528$ and $b=0.466$.

Thus the equation takes the form (Smit et al., 1998):

$\mathrm{CV}=10^{1.528+0.466 \log p}$

with $p \geq 5.2655 \times 10^{-7}$.

\subsection{Ocean}

In the model, the ocean is non advective and therefore does not contribute to horizontal tracer transport. The ocean surface mixed layer receives deposition and looses substance through volatilisation, degradation and loss to the deep sea. In the model world, the latter process is caused by a seasonal change of the depth of the surface mixed layer.

\subsubsection{Air-water gas exchange}

Diffusive air-water exchange is calculated based on the twofilm model (Liss and Slater, 1974) and Mackay and Leinonen (1975) invoking two mass transfer coefficients in series, $U_{1}$ $\left(\mathrm{m} \mathrm{s}^{-1}\right)$ for the stagnant atmospheric boundary layer and $U_{2}$ $\left(\mathrm{m} \mathrm{s}^{-1}\right)$ for the stagnant water layer close to the air-water interface. These mass transfer coefficients are calculated as a function of wind speed using relationships by Mackay and Yuen (1983) as quoted in Schwarzenbach et al. (1993).

$U_{1}=0.065 \times \sqrt{(6.1+0.63 \times u)} \times 0.01$,

$U_{2}=0.000175 \times \sqrt{(6.1+0.63 \times u)} \times 0.01$,

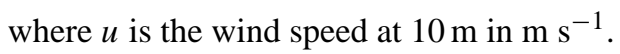

The D-values for volatilisation (cf. Schwarzenbach et al., 1993; Wania and Mackay, 1995, for definitions in the fugacity concept) from water are then calculated using the following equation:

$D_{w a}=\frac{1}{\frac{R \times T}{U_{1} \times Z_{A}\left(T_{W}\right)}+\frac{H}{U_{2} \times Z_{W}\left(T_{W}\right)}}$

where $R$ is the universal gas constant (8.3143 Joule mole ${ }^{-1} \mathrm{~K}^{-1}$ ), $T$ is the atmospheric temperature and $H$ is the Henry coefficient in units of $\mathrm{Pa} \mathrm{mol}^{-1} \mathrm{~m}^{3}$. 
Table 1. Physico-chemical properties of DDT and $\gamma-\mathrm{HCH}$ used for the model simulations.

\begin{tabular}{|c|c|c|c|}
\hline Physico-chemical property & Unit & DDT & $\gamma-\mathrm{HCH}$ \\
\hline Molecular mass & $\mathrm{g} \mathrm{mol}^{-1}$ & 354.5 & 290.83 \\
\hline Sorption coefficient & $\mathrm{m}^{3} \mathrm{~kg}^{-1}$ & 888 & 1.91 \\
\hline Saturated vapour pressure at $293 \mathrm{~K}$ & $\mathrm{~Pa}$ & $2.5 \times 10^{-5}$ & $3.0 \times 10^{-3}$ \\
\hline Heat of Vapourization & $\mathrm{J} \mathrm{mol}^{-1}$ & $118.0 \times 10^{3}$ & $115.0 \times 10^{3}$ \\
\hline Heat of Solution & $\mathrm{J} \mathrm{mol}^{-1}$ & $2.7 \times 10^{4}$ & $2.7 \times 10^{4}$ \\
\hline Water solubility at $296 \mathrm{~K}^{\mathrm{a}}$ & $\mathrm{mg} \mathrm{l}^{-1}$ & $3.4 \times 10^{-3}$ & 7.4 \\
\hline Ocean water solubility & $\mathrm{mg}^{-1}$ & $3.4 \times 10^{-3}$ & 7.4 \\
\hline Biotic and abiotic degradation rate in soil at $273 \mathrm{~K}$ & $s^{-1}$ & $4.05 \times 10^{-9}$ & $2.0 \times 10^{-8}$ \\
\hline Biotic and abiotic degradation rate in ocean at $273 \mathrm{~K}$ & $\mathrm{~s}^{-1}$ & 0 & $1.86 \times 10^{-8}$ \\
\hline $\mathrm{OH}$ radical rate constant of gaseous molecule & $\mathrm{cm}^{3}$ molecules ${ }^{-1} \mathrm{~s}^{-1}$ & $\mathrm{~b}_{4.5 \times 10^{-12}}$ & $1.9 \times 10^{-13}$ \\
\hline $\mathrm{OH}$ radical rate constant on particle sorbed molecule & $\mathrm{cm}^{3}$ molecules ${ }^{-1} \mathrm{~s}^{-1}$ & $\begin{array}{c}\mathrm{c}_{1.0 \times 10^{-13}} \\
\mathrm{~b}_{4.5 \times 10^{-12}} \\
\mathrm{c}_{0}\end{array}$ & 1950 \\
\hline
\end{tabular}

${ }^{\mathrm{a}}$ land and ocean water, ${ }^{\mathrm{b}}$ DG80LW, ${ }^{\mathrm{c}}$ all other DDT scenarios.

\subsubsection{Degradation}

Biological and abiotic degradation in ocean is assumed to obey first order kinetics, and assumed to double per $10 \mathrm{~K}$ temperature increase. The mathematical formulation has the form:

$k_{\text {ocean }}=k_{273} \times 2^{\frac{(T-273)}{10}}+k_{\text {hydr }} \times e^{\frac{-7818}{T}}$

\subsection{Deposition to soil, vegetation and ocean}

Dry deposition flux is calculated from the concentration in the lowest atmospheric layer and dry deposition velocity:

$F_{d}=c \times \rho_{\text {air }} \times v_{d}$,

where $\mathrm{c}$ is the tracer concentration $\left(\mathrm{kg} \mathrm{kg}^{-1}\right)$ at the surface layer, $\rho_{\text {air }}$ is the air density $\left(\mathrm{kg} \mathrm{m}^{-3}\right)$ and $v_{d}$ is the dry deposition velocity $\left(\mathrm{m} \mathrm{s}^{-1}\right)$.

The dry deposition velocity for gas phase is calculated according to the "big-leaf" approach by Hicks et al. (1987), where the turbulent transfer and vegetation activity is calculated by ECHAM, using the provided global uptake rates for soil, water, and snow/ice. Uptake resistance for the trace gases, for which the dry deposition velocities have not been observed or estimated, are calculated based on the Henry coefficient and a reactivity coefficient (Ganzeveld and Lelieveld, 1995; Ganzeveld et al., 1998), implying that water solubility controls the surface resistance. Scavenging of gaseous molecules is calculated based on the liquid fraction of the total substance derived from Henry's law (Seinfeld and Pandis, 1998). Particle dry deposition is calculated using a dry deposition velocity model, which has been applied previously for sulfate aerosol dry deposition parameterization (Ganzeveld et al., 1998). The particulate phase wet deposition is calculated based on a composition-dependent scavenging coefficient, which is defined as the fraction of the tracer in the cloudy part of the grid box that is embedded in the cloud liquid water or ice.

\section{Input data and model run initialisation}

The physico-chemical properties of DDT and $\gamma-\mathrm{HCH}$ are based on data compilations (Rippen, 2000; Klöpffer and Schmidt, 2001) and given in Table 1. DDT is represented as the $p, p^{\prime}$-DDT isomer. Data for DDT and $\gamma$-HCH usage are compiled based on statistical data on insecticide consumption in agriculture reported by each country to FAO (1947-1990) and also on published data (FAO, 1988, 1989). Data for most European countries for the study period are taken from Pacyna et al. (1999). The country-wise consumption data are distributed over the corresponding model grid through allocation of grid cells to countries scaled by the intensity of cropland distribution $\left(1^{\circ} \times 1^{\circ}\right.$ resolution; $\left.\mathrm{Li}, 1999\right)$ of the country, i.e. higher consumption is assumed in areas of high cropland density and vice versa.

\section{Scenarios}

A model simulation is performed for $10 \mathrm{a}$, after a physical spin-up of 8 a. Substance input into the model environment is the same every year. Even though this is not a realistic scenario, these experiments simulate the residence time of the substances in the total environment, the long-range transport potential, geographical distribution in atmosphere, soils, vegetation, and the ocean surface layer, and the vertical distribution in the atmosphere (top at $10 \mathrm{hPa}$, i.e., until $\approx 30 \mathrm{~km}$ on a global average).

Five scenarios, four for DDT and one for $\gamma-\mathrm{HCH}$ were run (Table 2). The latter is based on 1980 usage, while for DDT 
Table 2. Scenarios of DDT and $\gamma-\mathrm{HCH}$. ad=adsorption, $\mathrm{ab}=\mathrm{absorption}$.

\begin{tabular}{|c|c|c|c|c|c|c|}
\hline Substance & Scenario & Year & $\begin{array}{c}\text { Gas-particle } \\
\text { partitioning } \\
\text { process }\end{array}$ & $\begin{array}{l}\text { Applied } \\
\text { amount } \\
\left(\mathrm{t} \mathrm{a}^{-1}\right)\end{array}$ & $\begin{array}{l}\text { Period of } \\
\text { application }\end{array}$ & $\begin{array}{l}\% \text { applied to } \\
\text { vegetation/soil/ } \\
\text { atmosphere }\end{array}$ \\
\hline \multirow{4}{*}{ DDT } & DG80LW & 1980 & $a b$ & 9299 & Feb.-Sep. & $80 / 20 / 0$ \\
\hline & DG80HM & 1980 & ad & 9299 & Jan-Dec & $80 / 20 / 0$ \\
\hline & DG90HA & 1990 & $\mathrm{ad}$ & 4498 & June-July, Nov-Dec & $80 / 10 / 10$ \\
\hline & DG90HM & 1990 & ad & 4498 & June-July, Nov-Dec & $80 / 20 / 0$ \\
\hline$\gamma-\mathrm{HCH}$ & LG80HM & 1980 & ad & 20365 & Jan-Dec & $80 / 20 / 0$ \\
\hline
\end{tabular}

the scenarios reflect 1980 (DG80LW, DG80HM scenarios) and 1990 (DG90HM, DG90HA) usage. Non-agricultural usage is not captured by the data. In 1990 India was the dominant emitter, accounting for more than $75 \%$ of the total global consumption. Under the 1990 usage scenarios we neglect usage outside India and focus on this country in order to investigate transport and fate from this region. Application is during June, July, November and December, which are the main pre-harvesting months in India. We study two release scenarios, with (10\%) and without release into air.

Because significant discrepancies between reported data exist and some data are missing, we make an effort to account for these uncertainties by the design of the scenarios DG80LW and DG80HM: DG80LW stands for a lower and DG80HM for a higher estimate with respect to expected overall lifetime. Emission into air follows application during dry daylight hours only (DG80LW) or application evenly distributed throughout $24 \mathrm{~h}$ per day (DG80HM). By this discrimination a lower (DG80LW) or higher (DG80HM), respectively, fraction of the amount emitted into air is subject to immediate wash-out and, hence, transfer to ground compartments where the substance is longer lived. Atmospheric degradability is estimated rather high (DG80LW: $\mathrm{k}_{\mathrm{OH}}=4.5 \times 10^{-12} \mathrm{~cm}^{3}$ molecules ${ }^{-1} \mathrm{~s}^{-1}$ in gas and particulate phases) or low (DG80HM: $1.0 \times 10^{-13} \mathrm{~cm}^{3}$ molecules ${ }^{-1} \mathrm{~s}^{-1}$ in the gas-phase and zero in the particulate phase). Furthermore, partitioning to the particulate phase is due to absorption (DG80LW) or due to adsorption alone (DG80HM).

\section{Results and discussion}

\subsection{Global distributions and filling of compartments}

The runs allow to study the transition to quasi-steady state. Quasi-steady state is expected once the substance sinks in a compartment balances the sources. The dynamics of compartmental filling varies for different compartments and substances (Fig. 1), e.g. biotic degradation, transport to the deep sea and volatilisation are the sinks in the ocean compartment to balance the only source, i.e. atmospheric deposition. Ap- plication, and deposition are the sources and volatilisation and chemical degradation are the sinks in the soil and vegetation compartments. Volatilisation from the ground compartments are the source and depositions (wet and dry) and photolysis are the loss processes in the atmosphere (cf. Fig. $1)$.

The atmosphere and vegetation compartments reach quasisteady state in 3-4 a in the case of DDT, while it takes less than $2 \mathrm{a}$ in the case of $\gamma$-HCH (Fig. 1). In soil, DDT shows a tendency to reach equilibrium after slightly more than $10 \mathrm{a}$ while $\gamma-\mathrm{HCH}$ approaches equilibrium in $8 \mathrm{a}$. The substances behave significantly different in sea surface layer compartment. The accumulation of hydrophobic DDT is slower and the simulated time to achieve equillibrium is shorter, ca. $6 \mathrm{a}$, while the higher water solubility and low volatility of $\gamma-\mathrm{HCH}$ causes a high accumulation, reaching quasi-steady state in ca. $10 \mathrm{a}$. In the 10 th year, half of the DDT in the total environment is found in the soils (Table 3). Under the high mobility scenarios $12 \%$ is found in the ocean surface layer and ca. $5 \%$ in air, while under the low mobility scenario these burdens amount to only 2 and $1 \%$, respectively. As a consequence of differences in volatility and water solubility between the substances, a much smaller fraction of the total environmental burden of $\gamma-\mathrm{HCH}$ than of DDT is found on vegetation surfaces and a higher fraction in the ocean surface layer (Table 3). Until this 10th year upon entry of the substances, large amounts had been transferred to the deep sea, namely 2.5 times the total burdens of sea surface layer, air, soil and vegetation compartments or 2 times the annual applied amounts in the case of $\gamma-\mathrm{HCH}$ and 5 times the total burden or 6-7 times the annual applied amounts of DDT.

The fast atmospheric degradation in the case of DG80LW destroys $7170 t$ of DDT globally and annually (10th year) in contrast to only $16 \mathrm{t}$ in the case of DG80HM (related to $9299 \mathrm{t}$ applied annually). This discrepancy is obviously caused by the difference in $\mathrm{k}_{\mathrm{OH}}$ (both gas and particulate phases) and the partitioning to aerosols, which both affect residence time in air. This stresses the significance of the atmospheric decay: It dominates the further environmental fate even for a substance like DDT which is hardly volatile and, hence, 

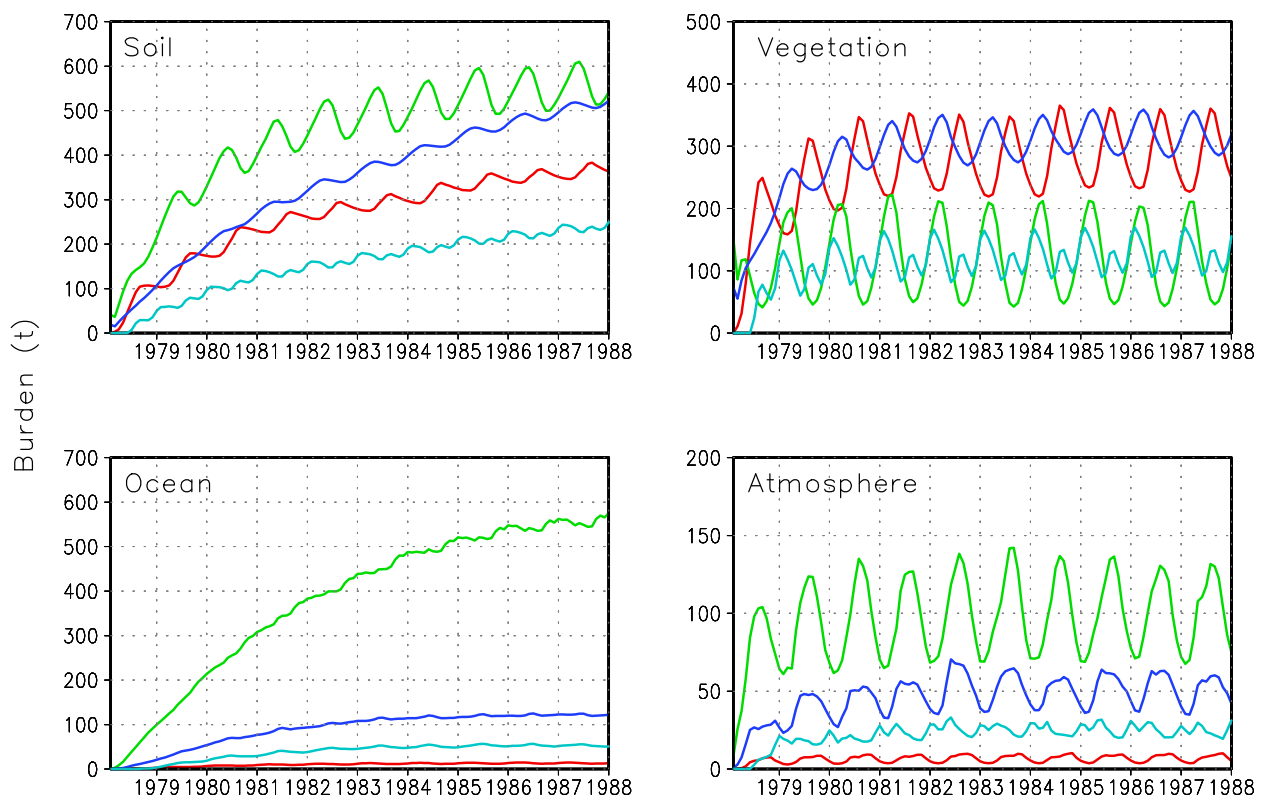

Fig. 1. Global burdens of DDT and lindane (t) over time (10 a) in soils, vegetation, ocean surface mixed layer, and the atmosphere under the scenarios DG80LW (red), DG80HM (dark blue), DG90HA (cyan), and LG80HM (green).

Table 3. Total environmental residence times, $\tau_{\text {overall }}(\mathrm{d})$, and compartmental distributions (\% mass, in brackets except for the Total environment: t) under various scenarios. Mean of the 10th year.

\begin{tabular}{cccccc}
\hline Scenario & Soil & Vegetation & Ocean surface layer & Atmosphere & Total environment \\
\hline DG80LW & $429(54 \%)$ & $134(43 \%)$ & $126(2.0 \%)$ & $3(1.0 \%)$ & $354(8153 \mathrm{t})$ \\
DG80HM & $523(51 \%)$ & $143(32 \%)$ & $147(12 \%)$ & $20(5.0 \%)$ & $485(12216 \mathrm{t})$ \\
DG90HA & $564(54 \%)$ & $111(28 \%)$ & $147(12 \%)$ & $22(5.6 \%)$ & $430(5350 \mathrm{t})$ \\
LG80HM & $212(42 \%)$ & $24(9 \%)$ & $288(42 \%)$ & $18(7.5 \%)$ & $287(16270 \mathrm{t})$ \\
\hline
\end{tabular}

hardly partitioning to the atmosphere in the multicompartment system.

The geographic distributions (Fig. 2) show maxima in or near the application area in all compartments and all experiments. The difference between the low and high mobility scenarios for DDT is very significant (DG80LW vs. DG80HM). This is due to the difference in atmospheric lifetime (Table 3). If horizontal transports in ocean had not been neglected as done in this study, the differences between the two simulations would be smaller, albeit supposedly only little on decadal time scales, because transport in ocean is much slower than in air. The geographical extension of distributions in air and sea water under the DG90HA scenario is much larger than that of the global emission scenario, DG80LW. This stresses that a slow atmospheric degradation favours long-range transport and longer residence times in the multicompartment environment and can easily overcompensate for a small source region. Within 10 a the entire northern hemisphere and part of the southern hemisphere is contaminated with DDT, while the whole global environment is filled with $\gamma-\mathrm{HCH}$. A significant contamination of the Antarctic by $\gamma-\mathrm{HCH}$ is found, even though more than $50 \%$ of the $\gamma-\mathrm{HCH}$ usage took place north of $39^{\circ} \mathrm{N}$. In the atmosphere, $\gamma-\mathrm{HCH}$ seems to be more mobile than DDT.

The difference in the entry scenarios of DG90HA and DG90HM do not propagate into significant differences in the geographic distributions. Moreover, the differences in the global compartmental distribution between these scenarios are negligible. Therefore, for much of the following discussion we refrain from covering DG90HM as differentiated from DG90HA (e.g. only DG90HA listed in Tables 3, 4). However, transport differentiating between DDT regional cycling under the two scenarios will be discussed below (Sect. 6.3.3).

Most of the atmospheric burdens reside in the planetary boundary layer (PBL). The concentration decreases with increasing height in the troposphere but exhibits an increase in the upper troposphere where wet removal is low on a global 


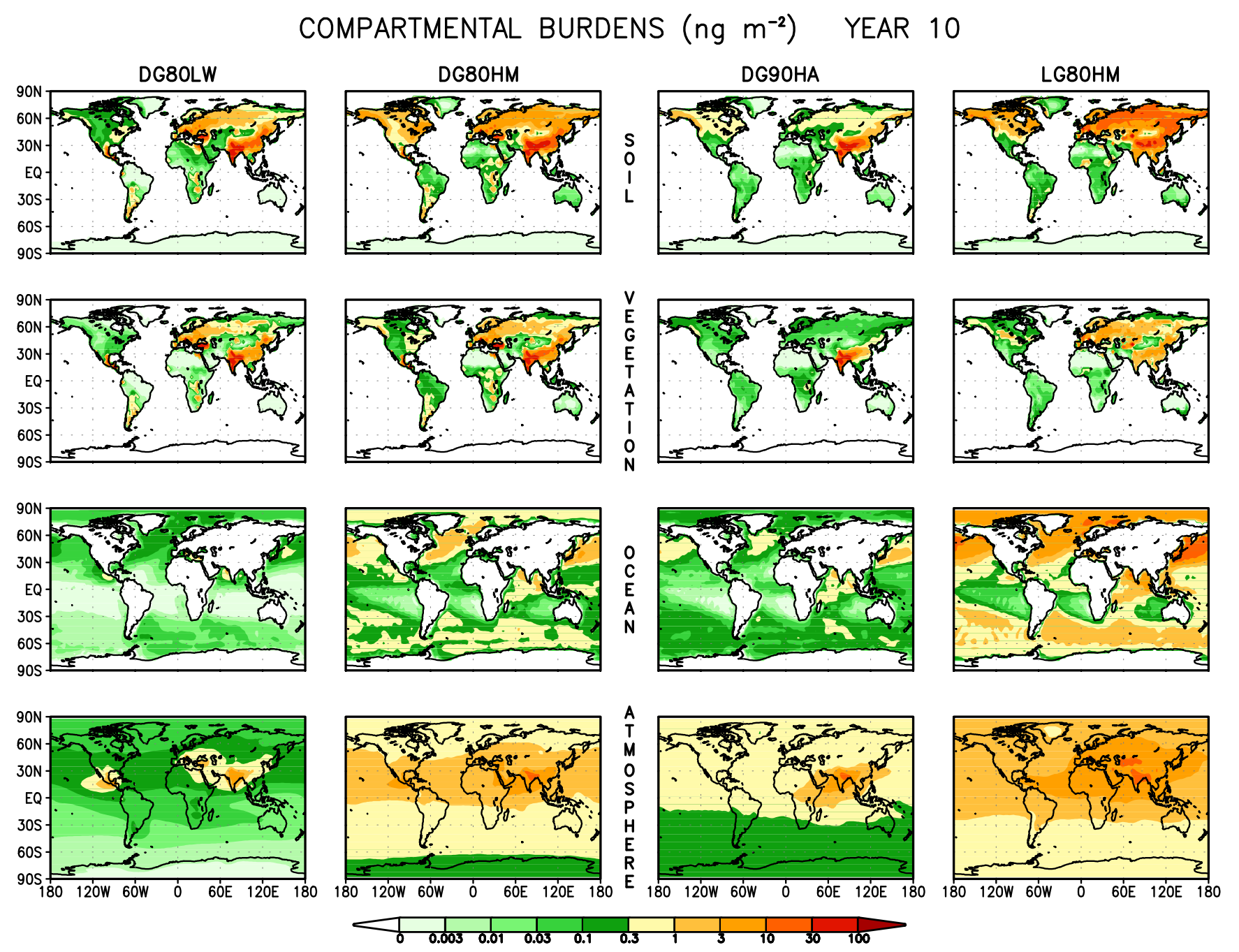

Fig. 2. Geographical distribution of burdens $\left(\mathrm{ng} \mathrm{m}^{-2}\right)$ in soil, vegetation, ocean and atmosphere for the scenarios DG80LW, DG80HM, DG90HA and LG80HM. Mean of the 10th year.

Table 4. Indicators for large-scale substance migration in the total environment. Mean of the 10th year.

\begin{tabular}{lcccc}
\hline Scenario & $\begin{array}{c}\text { lat }_{\mathrm{COG}} \\
\text { Application } \\
\left({ }^{\circ} \mathrm{N}\right)\end{array}$ & $\begin{array}{c}\text { lat }_{\mathrm{COG}} \\
\text { Total burden } \\
\left({ }^{\circ} \mathrm{N}\right)\end{array}$ & $\begin{array}{c}\text { Zonal } \\
\text { spreading (ZS) } \\
(\mathrm{km})\end{array}$ & $\begin{array}{c}\text { Spatial } \\
\text { spreading (SS) } \\
(\mathrm{km})\end{array}$ \\
\hline DG80LW & 23 & 27 & 1124 & 749 \\
DG80HM & 23 & 26 & 6945 & 4336 \\
DG90HA & 22 & 24 & 7993 & 7023 \\
LG80HM & 37 & 32 & 6672 & 5236 \\
\hline
\end{tabular}

average (Wallace and Hobbs, 1977) for all scenarios of DDT and for $\gamma-\mathrm{HCH}$ (Fig. 3). Washout limits atmospheric residence time in the $\mathrm{PBL}$, while reaction with the $\mathrm{OH}$ radical limits residence time aloft. In the stratosphere the sub- stance is expected to be almost completely associated with particulate matter. No such experimental evidence exists, though. As the degradability in this state was assumed zero for DG80HM but non-zero for DG80LW, the mixing ratio 
under the DG80LW but not under the high mobility scenarios is decreasing with height in the stratosphere. Almost identical profiles are found under the DG90HM and DG90HA scenarios, with slightly higher mixing ratios in the boundary layer as a consequence of assuming $10 \%$ loss into air upon application (Fig. 3).

\subsection{Global multicompartmental cycling}

The terrestrial compartments always show maxima of substance burden during the application months (Fig. 2) coinciding with a minimum in the atmospheric concentration. A secondary peak in the atmospheric burden during spring, i.e. the non-application months in the case of DG90HA corresponds to the peak volatilisation from soil, vegetation and ocean compartments (Figs. 2, 4a, b, c). During the post monsoon seasons the wet soil releases less substance back into the atmosphere, while a second maximum of volatilisation is found for the vegetation surfaces which coincides with a minimum in the vegetation compartmental burden. The volatilisation from ocean is prominent during the northern hemispheric summer (Fig. 3a), where most of the application takes place in all tested scenarios. Volatilisation from ocean is increasing over time under both the DDT and $\gamma-\mathrm{HCH}$.

The maximum storage in soil and vegetation compartments preceeded by 2-3 months of that of ocean, corresponds well with the minimum in atmospheric concentration in the case of $\gamma-\mathrm{HCH}$ (Fig. 1d). This is due to the efficient washout of more water soluble $\gamma-\mathrm{HCH}$, and also due to the faster atmospheric degradation due to the higher reactivity with $\mathrm{OH}$ radicals $\left(1.9 \times 10^{-13} \mathrm{~cm}^{3}\right.$ molecules $\left.{ }^{-1} \mathrm{~s}^{-1}\right)$ compared to that of DDT $\left(1.0 \times 10^{-13} \mathrm{~cm}^{3}\right.$ molecules $\left.{ }^{-1} \mathrm{~s}^{-1}\right)$. On a quantitative base, wet deposition dominates over dry deposition and hence the global average deposition patterns (Figs. 4d, e, f) resemble by and large the distribution of the globally averaged model precipitation (figure not shown).

The global mean residence times in the compartments are listed in Table 3. These are defined as:

$$
\tau_{i} \approx m_{i} /\left(E-\Delta m_{i} / \Delta t\right)
$$

with $m_{i}$ being the burden of the compound in compartment $i$, $E_{i}$ the total compartmental source and $\Delta m_{i} / \Delta t$ the net uptake $\left(t a^{-1}\right)$. As being the result of substance specific compartmental sinks and sources, $\tau_{i}$ is not predictable on the basis of degradation rates (cf. Table 1) alone. E.g., while two of the sinks to the $\gamma$-HCH's reservoir in the ocean surface layer are more effective than for DDT, namely faster degradation (Table 1) and loss to deep sea (28.5 kt against 6.9-8.6 kt for the various DDT scenarios, not shown), $\gamma-\mathrm{HCH}$ takes a middle position among the DDT scenarios in the case of the third compartmental sink, volatilisation from sea to air (Fig. 4c). The residence time of $\gamma-\mathrm{HCH}$ in ocean is still predicted to double the residence time of DDT. The difference in residence times in ocean is due to the stronger source for this compartment, i.e. atmospheric deposition (Fig. 4) which,

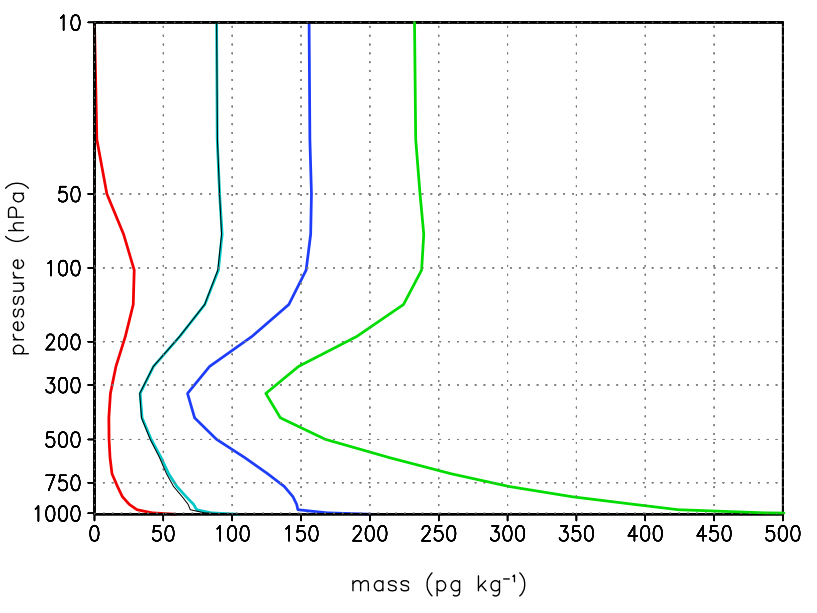

Fig. 3. Tenth year globally averaged vertical distribution in $\mathrm{pg} \mathrm{kg}^{-1}$ for DG80LW (red), DG90HA (cyan), DG90HM (black), DG80HM (dark blue), and LG80HM (green).

in turn, is due to the more efficient wash-out of $\gamma-\mathrm{HCH}$. One potentially significant process with respect to ocean residence time is neglected here, i.e. partitioning to ocean suspended particulate matter. Its recognition would further differentiate between the two substances, as a higher affinity of DDT (predicted based on the sorption coefficient to organic matter, cf. Table 1) would add more to the effectiveness of loss to the deep sea of DDT than of $\gamma-\mathrm{HCH}$. Therefore, it is suggested that the residence times of the substances in ocean surface layer are somewhat overestimated by the present model configuration and more so for DDT.

In contrast to the ocean surface layer, the model predicts longer residence times for DDT than for $\gamma-\mathrm{HCH}$ in the soil and vegetation compartments (Table 3 ). These result from stronger compartmental sinks for $\gamma-\mathrm{HCH}$, volatilisation (Fig. 4) and degradation (Table 1), which are obviously only partly compensated for by stronger sources for $\gamma$ $\mathrm{HCH}$, i.e. agricultural application (Table 2) and atmospheric deposition (Fig. 4). Together with the compartmental distribution (Table 3) these differences in compartmental residence times translate into a difference in total environmental residence time, $\tau_{\text {overall }}$, of the two substances: DDT's partitioning to the global soils and vegetation (82-87\% of the total reservoir) drives its total environmental residence time to higher values $(\approx 1.0-1.3$ a or $354-485 \mathrm{~d})$ than lindane $(\approx 0.8 \mathrm{a}$ or $287 \mathrm{~d}$ ). This is also because $\gamma$-HCH's partitioning to the compartment (ocean) with the longest residence time is not that pronounced ( $42 \%$ in the world oceans' surface layer). $\tau_{\text {overall }}$ is given as the sum of the compartmental residence times, $\tau_{i}$, weighted by the compartmental mass fractions or can be approximated similar to $\tau_{i}$ (Eq. 23) based on the total environmental burden, $m$, the total source to the system, $E$, and the total environmental net uptake, $\Delta m / \Delta t$.

The interpretation of the compartmental residence times of the various DDT scenarios shed light on the significance of 

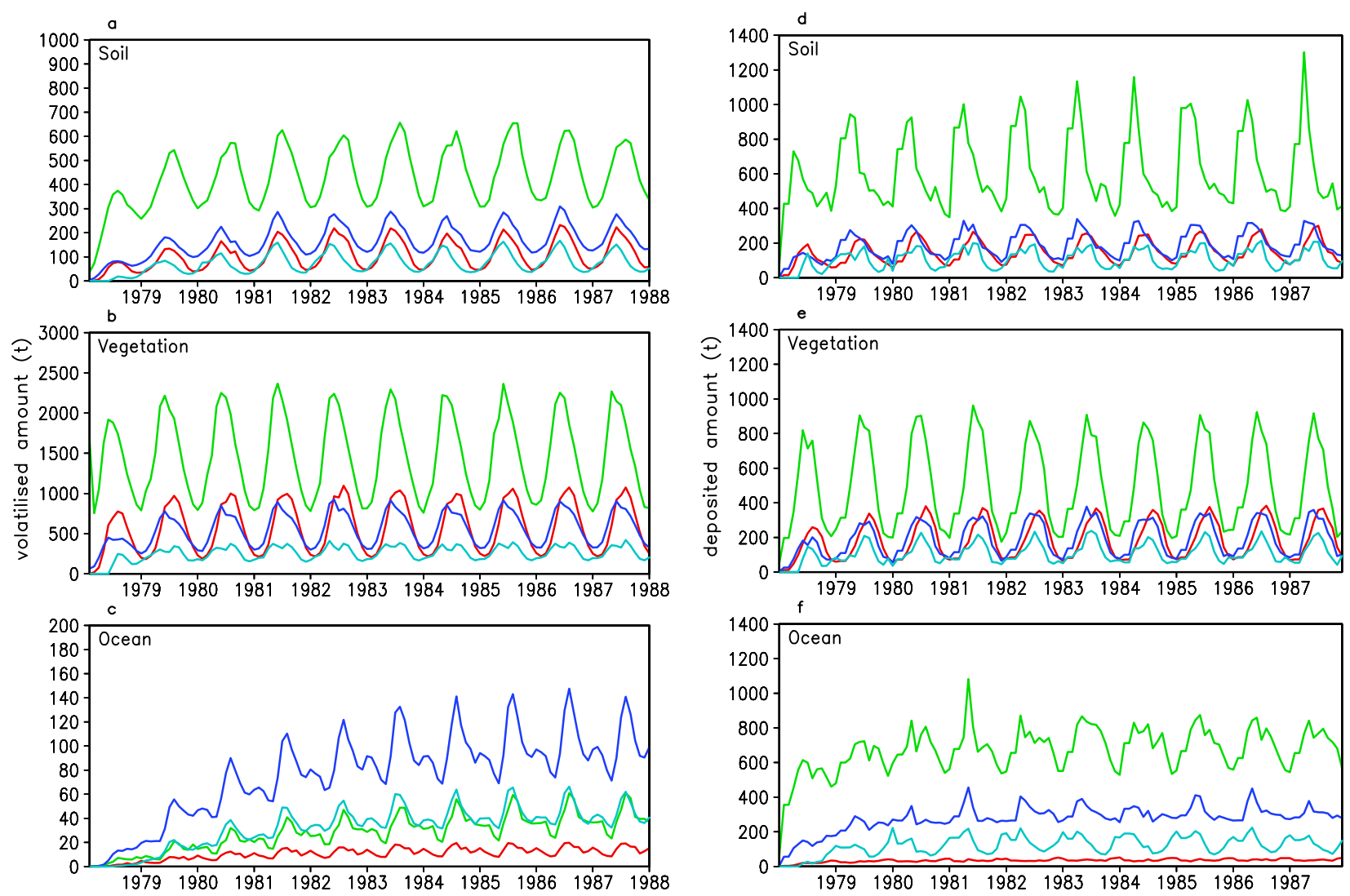

Fig. 4. Total volatilised (a, b, c) and deposited (d, e, f) amounts, t, from/to soil (a, d), vegetation (b, e) and ocean (c, f) for the scenarios DG80LW (red), DG90HA (cyan), DG80HM (blue), and LG80HM (green).

mode of entry of substances and the role of the atmosphere in multicompartmental cycling of organic compounds: DDT cycling under the scenarios DG80HM and DG90HA differs by the geographic and temporal application patterns and the modal split upon entry, while DG80HM and DG80LW differ in sinks in air. The total environmental residence times, $\tau_{\text {overall }}$, of DG80HM and DG80LW differ by $35 \%$ (longest for DG80HM). Due to different assumptions on atmospheric degradation (Table 2), the difference in $\tau_{\text {atmosphere }}$ is much larger, a factor of 7 (Table 3). In contrast, the change of geographic and temporal application patterns (corresponding to 1980 and 1990 scenarios) is predicted to reduce $\tau_{\text {overall }}$ by decreasing the residence time in soil and vegetation only by $10-20 \%$. $10 \%$ substance loss to air upon entry causes an increase of the global and annual mean atmospheric burden by $2 \%$, but a reduced residence time in air, $\tau_{\text {atmosphere }}$.

Most of the aforementioned results were presented geographically aggregated as the global mean compartmental sources, sinks and distributions. Cycling between compartments, however, will of course be influenced by regional weather, expectedly leading to significant differences between climate zones and topographical characteristics for e.g. alpine and coastal regions. In the following sub-chapter we focus on long-range transport (LRT) towards the poles, the role of the monsoon and substance cycling in three regions exhibiting very different climates.

\subsection{Long-range transport and influence of regional climate}

\subsubsection{Long-range transport to polar regions}

Contaminants released in lower latitudes enter the Arctic through long-range transport on air and water currents, with the atmosphere being the primary pathway (AMAP, 2003; $\mathrm{Li}$ and Macdonald, 2005). Airborne transport to the Arctic takes place preferably in the "arctic haze" season, in late winter and early spring.

We quantify the long-range transport potential (LRTP) using indicators for substance migration (Table 4, Leip and Lammel, 2004). The zonal spreading, ZS, which quantifies the tendency of a distribution to spread in meridional direction, shows the highest value for the scenario DG90HA.

Long-range atmospheric meridional transport is significant. Even under the low mobility scenario a substantial fraction of DDT is transferred to the southern hemisphere. $0.13 \%(10.6 \mathrm{t})$ and $0.01 \%(0.8 \mathrm{t})$ of the total 
environmental burden are found in the Arctic (i.e. $\geq 66.5^{\circ} \mathrm{N}$ ) and Antarctic ( $\geq 66.5^{\circ} \mathrm{S}$, mean of 10th year), respectively, under the low mobility scenario in contrast to $0.68 \%$ (83t) and $0.07 \%(8.6 \mathrm{t})$, respectively, under the high mobility scenario DG80HM. The winter monsoon over India carries more substance into the south, resulting into a $0.05 \%$ of total burden residing in the Antarctic polar circle for DG90HA, while the fraction which reaches the Arctic is $0.5 \%$. 1.85\% (300 t) and $0.06 \%$ (9.8t) are reaching and residing over Arctic and Antarctic in the case of $\gamma-\mathrm{HCH}$. These fractions of $\gamma-\mathrm{HCH}$ again emphasize the substance's large mobility. Despite a more northwardly application of $\gamma-\mathrm{HCH}$ than DDT (the centres of gravity of the application patterns are at 37 and $22^{\circ} \mathrm{N}$, respectively) larger fractions are found in the high latitudes of the southern hemisphere. The centre of gravity (COG) of a compartmental or total environmental substance distribution is defined as the geographic location where $50 \%$ of the mass burden is south of lat $\mathrm{COG}$, and $50 \%$ east of lon $\mathrm{COG}_{\text {. Obvi- }}$ ously, the larger mobility is important in this regard (which is driven by a higher saturation pressure and a smaller affinity to organic phases, e.g. sorption coefficient, Table 1). But the two substances also differ with respect to atmospheric deposition: $\gamma$-HCH is more efficiently washed out. $2 \%$ and $0.1 \%$ of the global deposition of DG80LW is received by the Arctic and Antarctic, respectively, while these fractions are $8 \%$ and $0.6 \%$, respectively, under the DG80HM scenario and 3\% and $0.4 \%$, respectively, under the DG90HA scenario. The respective fractions for $\gamma-\mathrm{HCH}$ are $21 \%$ and $0.4 \%$. The discrepancies in these fractions are explained by the residence time in air (DG80LW vs. DG80HM), more northward application of $\gamma$-HCH (DG80HM vs. LG80HM) and the superposition of temporal application and precipitation patterns (DG80HM vs. DG90HA, see Sect. 6.4). More northward applications will facilitate higher depositions in the north and less in the south.

The distributions of DDT and $\gamma-\mathrm{HCH}$ tend to migrate in the same zonal directions, northwards: The movement of lat ${ }_{\mathrm{COG}}$ of the total environmental burden (difference between the maximum shift to south and north) is $4.5^{\circ}, 6.2^{\circ}$ and $7.6^{\circ}$ towards N under the DG80LW, DG90HA and DG80HM scenarios, respectively, in $10 \mathrm{a}$. In the same time period the lat $_{\mathrm{COG}}$ of total environmental burden of $\gamma-\mathrm{HCH}$ has moved $4.4^{\circ}$ towards south from that of application $\left(37^{\circ} \mathrm{N}\right)$, but $6.7^{\circ}$ towards north from the first year in the environment. These migrations amount to $6.7^{\circ}, 12.2^{\circ}$ and $5.0^{\circ}$ towards $\mathrm{N}$ under the DG80LW, DG90HA and DG80HM scenarios, respectively (Fig. 5). Hence, the migratory tendency of the total environmental burden is most pronounced for DDT as used in 1990, less for lindane and even less for DDT as used in 1980. With a slower atmospheric degradation of DG80HM scenario, we expected a larger shift in COG of this scenario compared to DG80LW. But it is found that even though the plume spread is wider in DG80HM $(90 \%$ of mass lies between the latitudinal belts of $37.2^{\circ} \mathrm{S}$ and $60.7^{\circ}$ ) than in DG80LW (90\% mass is between 10.2 and $54.1^{\circ} \mathrm{N}$ ), the

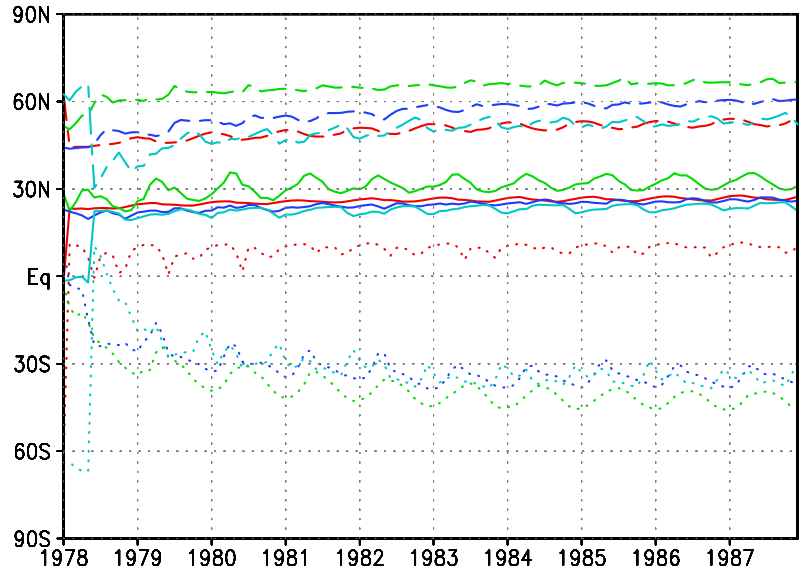

Fig. 5. Distribution of mass between latitudes. Migration of lat $_{05}$ (dotted lines), lat 50 (solid lines) and lat 95 (broken lines) percentiles, for DG80LW (red), DG80HM (blue), LG80HM (green) and DG90HA (cyan).

northward migration of the COG of the total environmental burden under the DG80LW scenario exceeds the one under the DG80HM scenario (Table 4). Although DDT is emitted only from India under the DG90HA scenario, the spreading is equally efficient as under DG80HM, where, by the end of the 10th year, $90 \%$ of the mass is found between $29.1^{\circ} \mathrm{S}$ and $52.1^{\circ} \mathrm{N}$ latitudes. At the end of $10 \mathrm{a}, 90 \%$ of $\gamma-\mathrm{HCH}$ is distributed between $45.7^{\circ} \mathrm{S}$ and $66.7^{\circ} \mathrm{N}$ latitudes (Fig. 5).

Under the high mobility scenario a spatial spreading of ca. $4500 \mathrm{~km}$ is found for DDT and ca. $5200 \mathrm{~km}$ for $\gamma-\mathrm{HCH}$. The LRTP as measured by the spatial spreading, SS, is higher for $\gamma$-HCH than DDT (Table 4).

\subsubsection{Influence of the regional climate}

Indian summer monsoon - when the wind blows from SW - is characterized by very heavy rainfall. This SW monsoon begins on the Kerala coast of India usually within two weeks of 1 June. The NE monsoon in boreal winter associated with dry conditions begins typically in October (Blandford, 1886; Webster et al., 1998; Gadgil, 2003). During the winter monsoon, low-level transport from the Indian subcontinent is particularly important. The aerosol load over India and the northern Indian Ocean is dominated by anthropogenic aerosols during the NE winter monsoon season and by mineral dust and sea salt during the SW summer monsoon. The former is dominated by low-level transport from $\mathrm{S}$ and $\mathrm{SE}$ Asia, while the latter results from low to mid tropospheric transport from the African continent and the Arabian Peninsula ( $\mathrm{Li}$ and Ramanathan, 2002). The global atmospheric burden and the zonally averaged distribution of DDT in the atmosphere during boreal summer (June-July) and winter (November-December) are shown in Fig. 6. Heavy precipitation during the summer monsoon reduces the atmospheric 

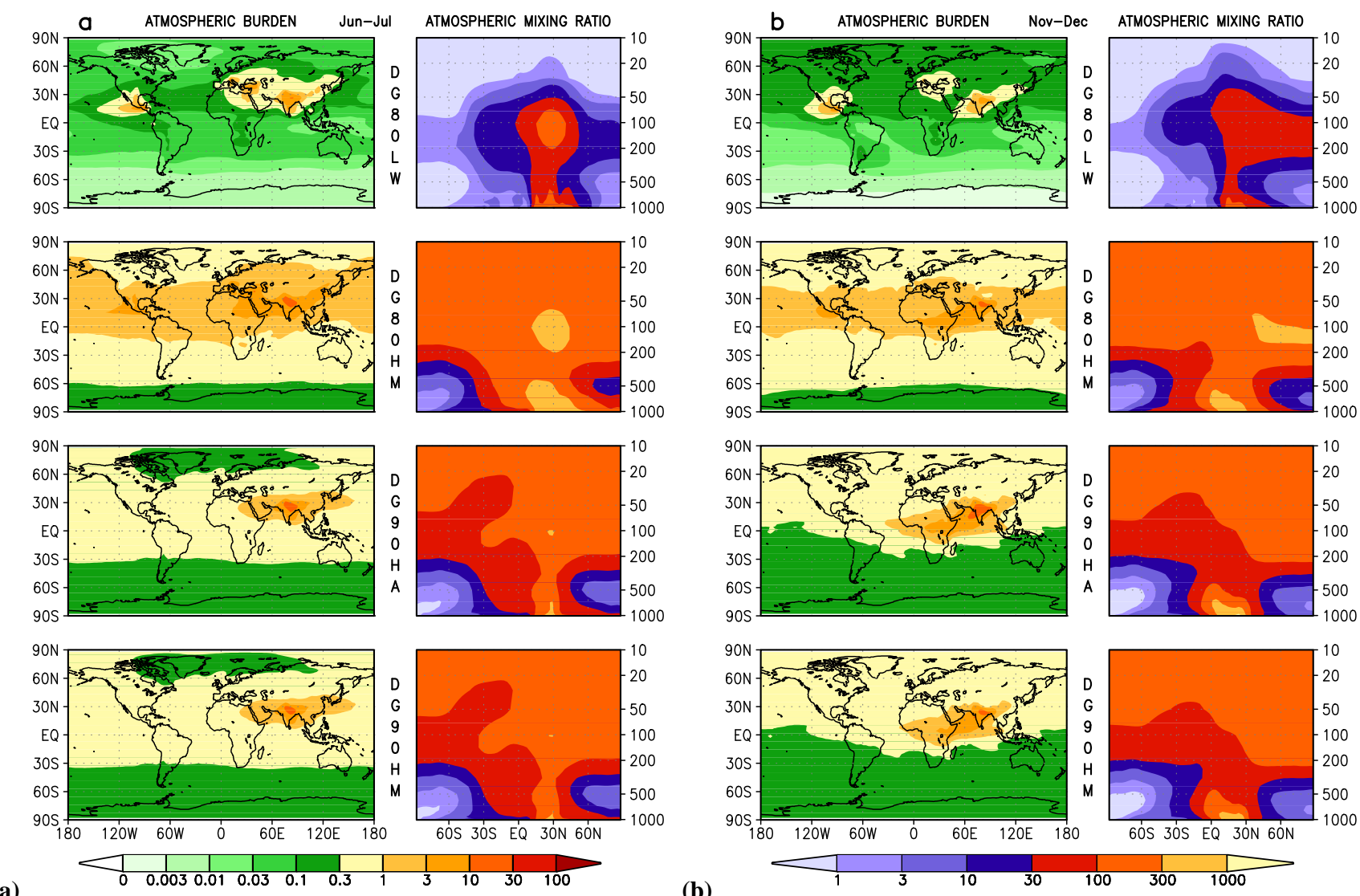

(b)

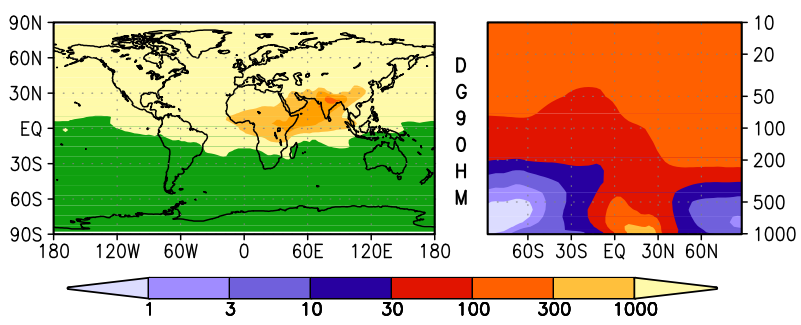

Fig. 6. June-July (a) and November-December (b) average geographic distribution of the DDT total atmospheric burden (ng $\mathrm{m}^{-2}$ ) and zonally averaged vertical mixing ratio profiles $\left(\mathrm{pg} \mathrm{kg}^{-1}\right.$ ) under the four scenarios, 10th year. Colour bars apply to both (a) and (b) each.

residence time of substances and subsequently their spread to remote regions. Pollution is carried to the NE (Fig. 6a). During the NE monsoon season mass is shifted more towards equator and towards west due to the northeasterly winds (Fig. 6b). In the vertical not much substance escapes into the stratosphere during the SW monsoon period due to the efficient washout. More substance is found to reach the stratosphere during the winter monsoon when pollution is transported over the Indian Ocean and mixed into the intertropical convergence zone (Fig. 6b). The plume from the major source regions, is shifted towards NE over Asia, more meridionally over Europe (due to midlatitude westerlies) and eastward over central America (due to trade winds). Here we assumed the substance to enter the model world during the peak monsoon months when it is washed out efficiently (Table 2). Even though substance is entried again during November and December, the monsoon causes again washout during November, leading only substance released in December to remain. That means that much of what is applied stays in the region. Test runs with a modified DG90HA scenario, namely continuous year-around temporal application pattern show that $\tau_{\text {atmosphere }}$ would be prolonged by $50 \%$ to ca. 34 days.
To study the various interactions between airborne transport, sink processes in the atmosphere and revolatilisation from the soil and from water surfaces and substance properties on substance fate as well as the seasonal and the interannual variability of climate parameters, we focus into two tropical regions, $6-29^{\circ} \mathrm{N} / 67-93^{\circ} \mathrm{E}$ and $9^{\circ}-0^{\circ} \mathrm{S} / 98-161^{\circ} \mathrm{E}$ and one high-latitude region, $50-64^{\circ} \mathrm{N} / 159-226^{\circ}$ E. Henceforth these are referred to as the Indian, Indonesian and Alaskan regions, respectively. The size of these regions is comparable (about $6.5 \times 10^{6} \mathrm{~km}^{2}$ ) and each of these encompasses land and sea areas of about equal size. The Indian region encompasses most of India south of the Himalayas and Bangla Desh and is a region with DDT and lindane application under the simulated scenarios in contrast to the other two regions. (The Indonesian region is chosen to exclude application areas of lindane in the northern parts of the archipelago.) The Alaskan region encompasses parts of eastern Siberia and Kamchatka and excludes the permafrost regions. The regions are characterized by significant (Indian, Alaskan) or very little (Indonesian) seasonal fluctuating temperatures (Fig. 7a) and by very high (Indian, Indonesian) (Nanjundiah et al., 1992; Hendon, 2002; Goswami, 2005) or low (Alaskan) precipitation rates (Stafford et al., 2000) 

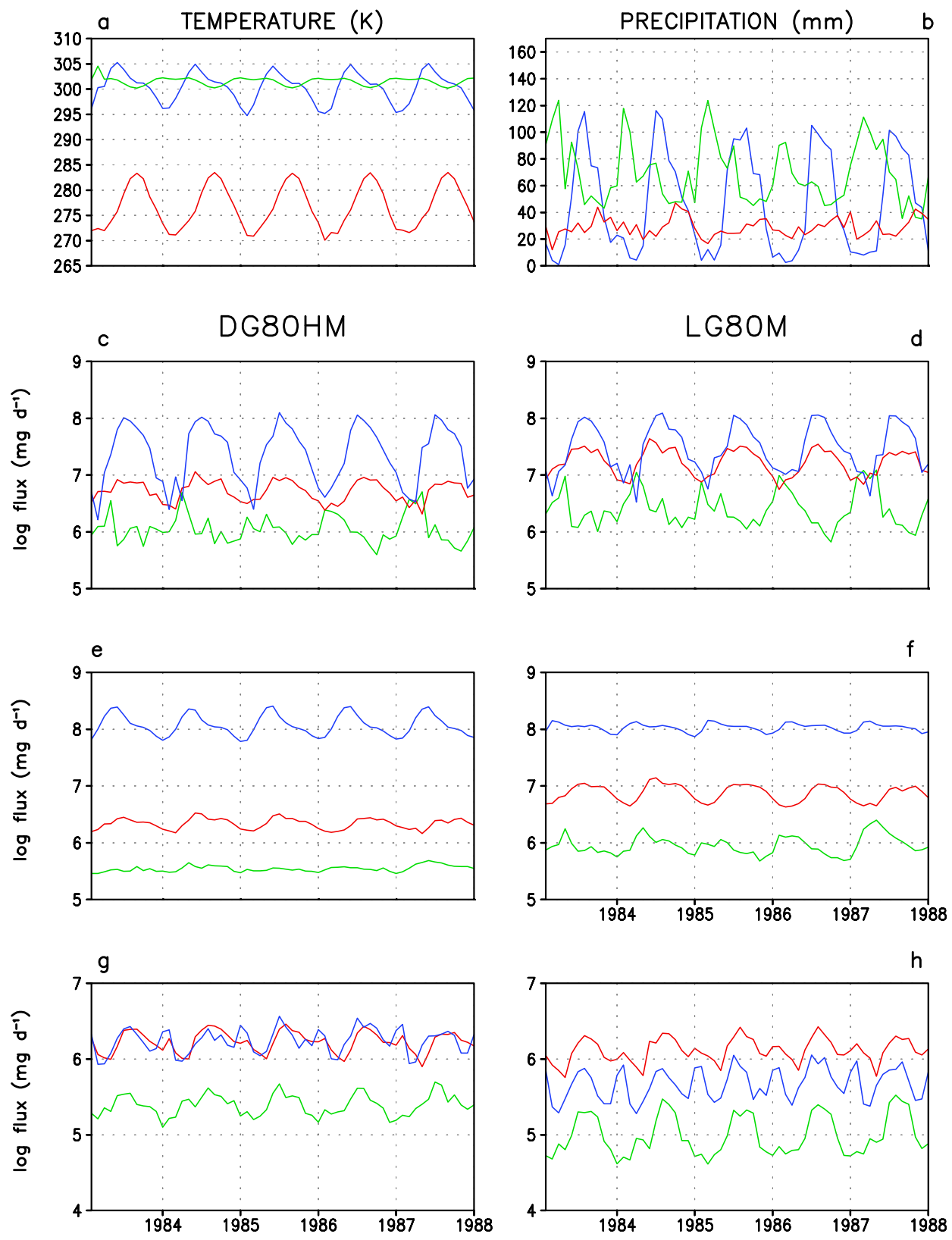

Fig. 7. Seasonality of the temperature at ground (a), precipitation (b), deposition (c, d), and volatilisation from land (e, f) and ocean (g, h) for DDT (c, e, g) and $\gamma-\mathrm{HCH}(\mathrm{d}, \mathrm{f}, \mathrm{h})$, in the Indian (blue), Indonesian (green) and Alaskan (red) regions during years 6-10 of the simulation.

(Fig. 7b), respectively. The austral summer monsoon brings heavy precipitation to Indonesia. The monsoon onset typically progresses in a southeastward direction from October through January. Monsoon retreat generally follows the opposite path, occurring from February through April (Tanaka, 1994). On interannual time scales precipitation over Indonesia has been shown to be strongly affected by ENSO and thus exhibits strong interannual variability. The model reproduces this interannual variability of Indonesian precipitation very well (see Fig. 7b).
The deposition of DDT in the Indian region is obviously determined, and in the Indonesian region at least influenced by the precipitation patterns: maxima of the time series coincide temporally as well as with respect to the magnitude. E.g., low precipitation in Indonesia in the year 8 of the simulation translates into a corresponding annual low in the DDT deposition flux (cf. Fig. 7c, "1985"). Dry deposition is more important in the dryer, extra-tropical region: The deposition maximum occurs up to 3 months in advance of the precipitation maximum in the Alaskan region (Fig. 7) and is related 
to the Arctic haze season in late winter and early spring. The volatilisation flux of DDT and $\gamma-\mathrm{HCH}$ in the Indian and Alaskan regions is obviously controlled by temperature, over land (cf. Figs. 7e, f), and by winds over ocean (Figs. 7g, h). Hereby, a relatively sharp peak coincides with the seasonal warming (April-May). However, this high volatilisation rate is not sustained during the entire warm season but decreases rapidly over India with the beginning of the rainy season. In contrast (and under conditions of little temperature fluctuations), it is the lack of precipitation (September-October) which triggers the volatilisation of DDT in the Indonesian region from land and ocean. Even though Indonesia is closer to source regions than Alaska, the deposition rate on and the volatilisation rate from this region is much smaller than those of Alaska. This is because Indonesia is upwind of the Indian source regions so that air masses containing pesticides applied in India has to circle the globe before reaching Indonesia. While deposition and volatilisation are correlated in Alaska (with time lags of up to 2 months), this is not the case in Indonesia, a finding which supports the determining influence of lack of precipitation for volatilisation in Indonesia. Also circulation in general transports the substance from the northern hemispheric source regions preferably to the north than across the equator, which explains the higher concentrations over Alaska compared to that over Indonesia.

Even more clearly than the deposition of DDT, the deposition of lindane in the tropical regions is obviously determined by the precipitation patterns. In the Alaska region, however, the deposition maxima of both DDT and lindane occur up to 3 months in advance of the precipitation maximum and are related to transport (seasonal winds). Much more $\gamma-\mathrm{HCH}$ is deposited there than DDT, a difference not seen in the tropical regions. This can be explained by the limited washout of DDT under conditions of reduced precipitation. Out of $194 \mathrm{t}$ of $\gamma$-HCH deposited over Indian region in the 10th year of the simulation, $159 \mathrm{t}$ are deposited during the wet months (June-November) while only to $35 \mathrm{t}$ during the dry months (December-May), and for DDT the corresponding deposition fluxes are 166, 133 and 33, respectively. The Indonesian wet months (December-May, Hendon, 2002) contribute 6t out of 8 in total of the deposited DDT, while it is $17 \mathrm{t}$ out of 20 in the case of $\gamma-\mathrm{HCH}$. In Alaska, the coastal regions experience relatively small variability, while the inland regions experience a continental climate with large daily and annual variability with respect to temperature and precipitation. Hence, we compare July-December as the months with more precipitation, with January-June as the ones with less precipitation. April is the driest month in all regions. $14 \mathrm{t}$ out of 21 of DDT and $44 t$ out of 75 of $\gamma$-HCH deposit during the wet period. These numbers show that in all the three regions considered, washout is the main removal mechanism from the lower troposphere.

The seasonalities of temperature and deposition flux in the Alaskan region, almost perfectly in phase, seem to explain the seasonality of substance volatilisation there. The volatil- isation flux of lindane in the tropical regions is controlled by precipitation in combination with temperature (Indian region) or precipitation, temperature and deposition (Indonesian region, cf. Fig. 7). Obviously, the higher volatility of lindane relative to DDT (vapour pressure) does not translate into a clear dependence of volatilisation on temperature fluctuation, but the superimposed influences are obviously more complex, causing different behaviour in different regions and for volatilisation from land and sea. The differences between the volatilisation patterns of the two substances are more pronounced on land. They are in phase in the receptor regions but out of phase in the source region India (despite the same temporal application pattern). This is due to the significance of the deposition pattern for volatilisation in the absence of the agricultural application as a source. As the Indian region is a major entry region for the substances into the environment, it is a net exporting region $\left(\mathrm{F}_{\mathrm{vol}}>\mathrm{F}_{\mathrm{dep}}\right)$. In contrast, the non-application regions are net-importing regions $\left(\mathrm{F}_{\mathrm{vol}}<F_{\text {dep }}\right)$. Deposition exceeds volatilisation by $167 \%$ and $208 \%$ in the Indonesian region for DDT and $\gamma-\mathrm{HCH}$, respectively, but by only $27 \%$ and $102 \%$, respectively, in the Alaskan region.

\subsection{Comparison with observations}

The scarcity of long-term measurements of DDT and $\gamma$ - $\mathrm{HCH}$ cause severe limitations to validate model results. Moreover, due to un-realistic usage scenarios (virgin environment, same amounts in sequential years), data uncertainties of physicochemical data, degradation data and temporal usage patterns, we can only expect model results to match observational data in terms of temporal and geographic trends rather than absolute numbers.

We compare model results with long-term measurements in the continental Arctic, which started in 1993 (Macdonald et al., 2000). As local SOCs cycling at the coastal Arctic stations (Iceland and Spitsbergen) will be strongly influenced by sea ice and its seasonality and the substance cycling in the model treats sea ice like sea water, we refrain from comparing with observations from these sites. Years with monitoring data were not simulated, nor was the temporal dynamics of the applied amounts. Therefore, any comparison of model data with observation is necessarily very uncertain. To come close to the historic years, we choose the atmospheric concentration data of the 3rd simulated year under the 1990 DDT scenario and the 10th simulated year under the 1980 scenarios (DDT and $\gamma-\mathrm{HCH}$ ). This is justified, since after a few years the modelled atmospheric concentration has reached quasi-steady state and does not change significantly thereafter (Fig. 1). The predicted concentrations overestimate the observed by a factor of 1.6 (Ny Alesund) - 26 (Tagish) in the case of DG90HA and by a factor of 38 (Ny Alesund) - 53 (Dunai and Heimaey) for $\gamma$-HCH (Table 5). In contrast, the simulated concentration under the DG80LW scenario is in good agreement with the observation. The discrepancy lies 
Table 5. Model simulated and observed concentration over Arctic $\left(\mathrm{pg} \mathrm{kg}^{-1}\right)$.

\begin{tabular}{l|ccc|cc}
\hline \multirow{2}{*}{ Location } & \multicolumn{3}{|c|}{ DDT } & \multicolumn{2}{c}{$\gamma-\mathrm{HCH}$} \\
& Simulated & Observed & \multicolumn{2}{c}{$\begin{array}{c}\text { Simulated } \\
\text { LG80HM }\end{array}$} & \\
\hline $\begin{array}{l}\text { Ny Alesund } \\
\left(78.55^{\circ} \mathrm{N}, 11.56^{\circ} \mathrm{E}\right)\end{array}$ & 5.1 & 8.6 & 5.4 & 543.3 & 14 \\
$\begin{array}{l}\text { Alert } \\
\left(82.30^{\circ} \mathrm{N}, 62.20^{\circ} \mathrm{E}\right)\end{array}$ & 3.7 & 10.8 & 4.3 & 551.9 & 11 \\
$\begin{array}{l}\text { Tagish } \\
\left(60.20^{\circ} \mathrm{N}, 134.15^{\circ} \mathrm{E}\right)\end{array}$ & 3.0 & 38.0 & 1.4 & 462.7 & 11 \\
$\begin{array}{l}\text { Dunai Island } \\
\left(74.00^{\circ} \mathrm{N}, 125.00^{\circ} \mathrm{E}\right)\end{array}$ & 5.8 & 7.2 & 0.93 & 515.4 & 9.8 \\
$\begin{array}{l}\text { Heimaey Island } \\
\left(63.24^{\circ} \mathrm{N}, 21.17^{\circ} \mathrm{E}\right)\end{array}$ & 3.1 & 1.6 & $\mathrm{nd}^{\mathrm{a}}$ & 799.0 & 15 \\
\hline
\end{tabular}

${ }^{a}$ Data not available or not determined

between $5 \%$ and a factor of 5.2. The seasonality of the atmospheric concentration is reasonably captured by the model for the continental Arctic station (Tagish). The predicted yearly amplitude (i.e. ratio of mean of maximum month to mean of minimum month) is 2.3 , while that of observed is 2 .

Global DDT usage in agriculture was supposedly around $5 \mathrm{kt}$ in the early 1990s ( $\mathrm{Li}$ and Macdonald, 2005) in contrast to 9.3 and $4.5 \mathrm{kt}$ under DG80LW and DG90HA, respectively. From this, overestimations up to a factor of 2 could be explained. However, the geographic application pattern of DDT had substantially changed between 1980 and the early 1990s, namely shifted south. From this, a tendency to overestimate Arctic DDT levels based on the northerly biased application pattern under DG80LW can be expected. The match between predicted and observed under DG80LW and the overestimate under DG90HA, therefore, are suggested to be related to compensating effects: An overestimated atmospheric source (emissions continuously on the high 1980 level) is compensated for by an overestimated distance to source regions and an overestimated atmospheric sink (too fast degradation). The model results under DG90HA might be deviating from observations due to an underestimated atmospheric sink (too slow degradation). Global $\gamma$-HCH usage had decreased to about $5.9 \mathrm{kt}$ in 1980 and slightly less in the following years (Li et al., 1996) in contrast to $20.4 \mathrm{kt}$ under LG80HM. Hence, annual emitted amounts during the observation period are expected to be a factor of 5 or so too high. The application pattern of $\gamma-\mathrm{HCH}$ changed less significantly. The discrepancies are larger than expected and might be related to partitioning to the cryosphere (not captured in the model) or to underestimated atmospheric sinks, as well. The $\mathrm{OH}$ radical reaction coefficient is not particularly uncertain, but the degradability on particulate matter (assumed to be 0) is.

\section{Conclusions and outlook}

The behaviour of SOCs in the environment was studied using a multicompartment model which is based on an AGCM. The prime aim of this study was to investigate the combined influences of global and regional climate on one hand side and physico-chemical properties of SOCs on the other hand side on the long-range transport potential and multicompartmental cycling on the temporal scale of a decade. Under five scenarios five combinations of physico-chemical properties and emission patterns (temporal and spatial) were tested.

The ground compartment reservoirs are mostly controlled by the balance between atmospheric deposition and (re-)volatilisation fluxes, because degradation is slow there. The transition to quasi-steady state could be simulated: The model predicts the atmosphere and vegetation compartment to reach pseudo-steady state within 3-4a, in the case of both DDT and $\gamma-\mathrm{HCH}$ and under all tested scenarios. DDT shows a tendency to reach equilibrium in slightly more than $10 \mathrm{a}$ in soil, while $\gamma-\mathrm{HCH}$ almost achieved quasi-steady state in $10 \mathrm{a}$. Our study does not address the longer time scale ( $>10$ a) nor does it account for transport with ocean currents. These, accounted for, would change the tracer distributions in the ocean mixed surface layer. The deep ocean is considered as the final sink for many pollutants. The ocean surface mixed layer is predicted to approach quasi-steady state with respect to DDT cycling within ca. $6 \mathrm{a}$ and with respect to lindane cycling within ca. one decade. Once this state is reached the compartmental sources (atmospheric deposition) are balanced by the sinks (volatilisation, degradation, loss to deep sea). In reality, in particular DDT volatilisation from the world ocean might be more delayed, because the model is expected to underestimate SOCs' loss to the deep sea, and more so for DDT than $\gamma-\mathrm{HCH}$, as it disregards the partitioning to sinking particulate matter. Due to the large gradients of the phytoplankton distributions (Yoder and Kennelly, 2003), 
this effect will be most significant close to continental margins and in shelf seas.

All environmental compartments are globally contaminated within 2 a. Expectedly, degradation in the atmosphere was found to be key for long-range transport. Even if the atmospheric burden accounts for only $1 \%$ of the total environmental burden, the total environmental persistence is significantly influenced by atmospheric degradation. The relative significances of various contributions to atmospheric degradation, $\mathrm{OH}$ reaction in the gaseous and particulate phases, phase partitioning remain to be investigated. These will be addressed in future studies and studies under way. Contaminant accumulation spreads more rapidly towards north than towards south. On the time-scale of a decade and under scenarios of stable spatial emission patterns a northerly shift is predicted for the large-scale migration of DDT and, more pronounced for the migration of lindane.

The role of regional wind systems and atmospheric dynamics in general are relevant for the understanding of SOCs cycling on large spatial scales. This study shed some light on the role of the dynamics over and around Asia: a high latitude region (like the Alaskan region) seems to act as a better sink region for SOCs than a region close to the source areas (like the Indonesian region). The role of trade winds is evident in this context, because once SOC-loaded air flows out from Asia during the boreal winter. Further on, substances reaching mid-latitudes, are partly transported further north. Low concentrations as well as elevated concentrations in the same latitudinal zone are predicted depending on whether regions being located downwind (such as equatorial Africa) or upwind (such as the Indonesian region) of source regions.

AGCM-based models should be capable to simulate the long-range transport as well as the influence of regional climate and climate change. It is important to provide tools capable to study multicompartmental cycling, LRTP and total environmental persistence, $\tau_{\text {overall }}$, since the measurement of these characteristics are impossible. As mentioned above, the organochlorine pesticides have been in use from the late 1940s, while monitoring started only by the late 1980s. The observations, hence, reflect the combined cycling of increasing fresh emissions and remnants from the earlier usage period. Therefore, a historic simulation with transient emission data is necessary to simulate the historic global cycling of these substances.

Acknowledgements. We thank U. Schlese and S. Rast for technical support and F. Guglielmo and P. Stier for valuable support and suggestions.

Edited by: F. J. Dentener

\section{References}

AMAP: The influence of global change on contaminant pathways to, within, and from the Arctic, Arctic Monitoring and Assessment Programme, Oslo, 2003.

AMAP: AMAP assessment 2002 - Persistent organic pollutants in the Arctic, Arctic Monitoring and Assessment Programme, Oslo, 2004.

Batjes, N. H.: Total carbon and nitrogen in the soils of the world, Europ. J. Soil Sci., 47, 151-163, 1996.

Bidleman, T. F., Patton, G. W., Hinckley, D. A., Walla, M. D., Cotham, W. E., and Hargrave, B. T.: Chlorinated pesticides and polychlorinated biphenyls in the atmosphere of the Canadian Arctic, chap. 23, pp. 347-372, In Kurz, D., Lewis Publ., Chelsea, UK, 1990.

Blandford, H. F.: Rainfall of India, Mem. India Meteor. Dept., 2, 217-448, 1886.

Boethling, R. S. and Mackay, D. (Eds.): Property estimation methods for chemicals: environmental and health sciences, CRC Press, Boca Raton, USA, 2000.

Drijfhout, S., Heinze, M., Latif, M., and Maier-Reimer, E.: Mean circulation and internal variability in an ocean primitive equation model, J. Phys. Oceanogr., 26, 559-580, 1996.

ECB: Technical Guidance Document in Support of The Commissions Directive 93/67/EEC on Risk Assessment for the Notified Substances and the Commission Regulation (EC) 1488/94 on Risk Assessment for Existing Substances, European Chemicals Bureau, Ispra, Italy, 1996.

Egan, W. G., Murphey, B. B., and Hogan, A. W.: Meteorological analysis of chemical exchange events in the Arctic Basin, Sci. Total Environ., 160/161, 87-99, 1995.

FAO: UN Food and Agricultural Organization Production Year books 1948-1988, FAO, Rome, 1988.

FAO: UN Food and Agricultural Organization Statistical data on insecticide consumption 1948-1988, FAO, Rome, 1989.

Feichter, J., Kjellström, E., Rodhe, H., Dentener, F., Lelieveld, J., and Roelofs, G.: Simulation of the tropospheric sulfur cycle in a global climate model, Atmos. Environ., 30, 1693-1707, 1996.

Finizio, A., Mackay, D., Bidleman, T., and Harner, T.: Octanolair partitioning coefficient as a predictor of partitioning of semivolatile organic chemicals to aerosols, Atmos. Environ., 31, 2289-2296, 1997.

Frische, R., Esser, G., Schönborn, W., and Klöpffer, W.: Criteria for assessing the environmental behavior of chemicals, Ecotox. Environ. Safety, 6, 283-293, 1982.

Gadgil, S.: The Indian Monsoon and its variability, Annu. Rev. Earth. Planet. Sci., 31, 429-467, 2003.

Ganzeveld, L. and Lelieveld, L.: Dry deposition parameterization in a chemistry general circulation model and its influence on the distribution of reactive trace gases, J. Geophys. Res., 100, 20 999-21 012, 1995.

Ganzeveld, L., Lelieveld, L., and Roelofs, G. J.: Dry deposition parameterization of sulfur oxides in a chemistry general circulation model, J. Geophys. Res., 103, 5679-5694, 1998.

Goswami, B. N.: South Asian Monsoon: In intraseasonal variability of the atmosphere-ocean climate system, chap. 2, pp. 19-61, Springer Berlin Heidelberg, 2005.

Hagemann, S., Arpe, K., and Roeckner, E.: Evaluation of the hydrological cycle in the ECHAM5 model, J. Climate, in press, 2006. 
Hansen, K. M., Christensen, J. H., Brandt, J., Frohn, L. M., and Geels, C.: Modelling atmospheric transport of persistent organic pollutants in the northern hemisphere with a three-dimensional dynamic model: DEHM-POP, Atmos. Chem. Phys., 4, 11251137, 2004.

Harner, T. and Bidleman, T. F.: Measurement of octanol-air partition coefficients for polychlorinated aromatic hydrocarbons and polychlorinated naphthalenes, J. Chem. Eng. Data, 43, 40-46, 1998.

Harner, T., Kylin, H., Bidleman, T. F., and Strachan, W. M. J.: Removal of alpha and gamma hexachlorocyclohexane and alpha hexachlorocyclohexane in the Eastern Arctic Ocean, Environ. Sci. Technol., 33, 1157-1164, 1999.

Hendon, H. H.: Indonesian rainfall variability: Impacts of ENSO and local air-sea interaction, J. Clim., 16, 1775-1790, 2002.

Hicks, B. B., Baldocchi, D. D., Meyers, T. P., Hosker, R. P., and Matt, D. R.: A preliminary multiple resistance routine for deriving dry deposition velocities from measured quantities, Water Air Soil Poll., 36, 311-330, 1987.

Junge, C. E.: Basic considerations about trace constituents in the atmosphere as related to the fate of global pollutants, pp. 7-26, Wiley, New York, 1977.

Kaupp, H. and Umlauf, G.: Atmospheric gas-particle partitioning of organic compounds: a comparison of sampling methods, Atmos. Environ., 26A, 2259-2267, 1992.

Klecka, G., Boethling, B., Franklin, J., Graham, D., Grady, L., Howard, P., Kannan, K., Larson, R., Mackay, D., Muir, D., and van de Meent, D. (Eds.): Evaluation of persistence and longrange transport of organic chemicals in the environment: Guidelines and criteria for evaluation and assessment, SETAC Press, Pensacola, USA, 2000.

Klöpffer, W. and Schmidt, E.: A multimedia load model for the Baltic Sea, Environ. Sci. Pollut. Res., 8, 180-188, 2001.

Koziol, A. and Pudykiewicz, J.: Global-scale environmental transport of persistent organic pollutants, Chemosphere, 45, 11811200, 2001.

Lammel, G., Feichter, J., and Leip, A.: Long-range transport and multimedia partitioning of semivolatile organic compounds: A case study on two modern agrochemicals, Max Planck Institute for Meteorology Report, vol. 324, Hamburg, Germany, 44 pp., 2001

Leip, A. and Lammel, G.: Indicators for persistence and long-range transport potential as derived from multicompartment chemistrytransport modelling, Environ. Poll., 128, 205-221, 2004.

Li, Y. F.: Global gridded technical hexachlorocyclohexane usage inventories using a global cropland as a surrogate, J. Geophys. Res., 104, 23 785-23 797, 1999.

Li, Y. F. and Macdonald, R. W.: Sources and pathways of selected organochlorine pesticides to the Arctic and the effect of pathway divergence on $\mathrm{HCH}$ trends in biota: a review, Sci. Total Environ., 342, 87-106, 2005.

Li, F. and Ramanathan, V.: Winter to summer monsoon variation of aerosol optical depth over the tropical Indian Ocean, J. Geophys. Res., 107, 4284, doi:10.1029/2001JD000949, 2002.

Li, Y. F., McMillan, A., and Scholtz, M. T.: Global HCH usage with $1 \times 1$ longitude/latitude resolution, Environ. Sci. Technol., 30, 3525-3533, 1996.

Liss, P. S. and Slater, P. G.: Flux of gases across the air sea interface, Deep Sea Res., 247, 181-184, 1974.
Macdonald, R. W., Barrie, L. A., Bidleman, T. F., Diamond, M. L., Gregor, D. J., Semkin, R. G., Strachan, W. M. J., Li, Y. F., Wania, F., Alaee, M., Alexeeva, L. B., Bailey, S. M. B. R., Bewers, J. M., Gobeil, C., Halsall, C. J., Harner, T., Hoff, J. T., Jantunen, L. M. M., Lockhart, W. L., Mackay, D., Muir, D. C. G., Pudykiewicz, J., Reimer, K. J., Smith, J. N., Stern, G. A., Schroeder, W. H., Wagemann, R., and Yunker, M. B.: Contaminants in the Canadian Arctic: 5 years of progress in understanding sources, occurrence and pathways, Sci. Total. Environ., 254, 93-234, 2000.

Mackay, D. and Leinonen: Rate of low solubility contaminants from water bodies ot atmosphere, Environ. Sci. Technol., 9, 1178-1180, 1975.

Mackay, D. and Yuen, A. T. K.: Mass transfer coefficients correlations of volatilisation of organic solutes from water, Environ. Sci. Technol., 17, 211-216, 1983.

Malanichev, A., Mantseva, E., Shatalov, V., Strukhov, B., and Vulykh, N.: Numerical evaluation of the polychlorinated biphenyls transport over the northern hemisphere, Environ. Poll., 128, 279289, 2004.

Nanjundiah, R. S., Srinivasan, J., and Gadgil, S.: Intraseasonal variation of the Indian summer monsoon. Part II: Theoretical aspects, J. Meteor. Soc. Jap., 70, 529-550, 1992.

Pacyna, J. M.: The origin of Arctic air pollutants: lessons learned and future research, Sci. Total Environ., 160/161, 39-53, 1995.

Pacyna, J. M., Wania, F., Breivik, K., and Pacyna, E.: Environment and Climate Research Programme (1994-1998). Appendix 1 to Execute Final Summary Report. Environmental cycling of selected persistent organic pollutants (POPs) in the Baltic Region, Tech. rep., Norwegian Institute for Air Research, Kjeller, Norway, 1999.

Pankow, J. F.: Review and comparative analysis of the theories on partitioning between the gas and aerosol particulate phases in the atmosphere, Atmos. Environ., 21, 2275-2283, 1987.

Pankow, J. F.: Common $\gamma$-intercept and single compound regressions of gas-particle partitioning data vs. 1/T, Atmos. Environ., 25A, 2229-2239, 1991.

Pontolillo, J. and Eganhouse, R. P.: The search for reliable aqueous solubility $\left(S_{w}\right)$ and octanol-water partition coefficient $\left(K_{o w}\right)$ data for hydrophobic organic compounds: DDT and DDE as a case study, Tech. rep., U.S. Geological Survey, Water-Resource Investigations Report 01-4201, Reston, Virginia, 2001.

Rippen, G.: Umweltchemikalien, Ecomed, Landsberg, Germany, 2000.

Roeckner, E., Oberhuber, J. M., Bacher, A., Christoph, M., and Kirchner, I.: ENSO variability and atmospheric response in a global coupled atmosphere-oceam GCM, J. Clim. Dyn., 12, 737754, 1996.

Roeckner, E., Brokopf, R., Esch, M., Giorgetta, M., Hagemann, S., Kornblueh, L., Manzini, E., Schlese, U., and Schulzweida, U.: Sensitivity of simulated climate to horizontal and vertical resolution in the ECHAM5 atmosphere model, J. Climate, in press, 2006.

Roelofs, G. J., Lelieveld, J., and Dorland, R.: A three-dimensional chemistry general circulation model simulation of anthropogenically derived ozone in the troposphere and its radiative climate forcing, J. Geophys. Res., 102, 23 389-23 401, 1997.

Schwarzenbach, R., Gschwend, P. M., and Imboden, D. M.: Environmental Organic Chemistry, Wiley, New York, 1993. 
Seinfeld, J. H. and Pandis, S. N.: Atmospheric chemistry and physics: from air pollution to climate change, WileyInterscience, 1998.

Smit, A. A. M. F. R., van den Berg, F., and Leistra, M.: Estimation method for the volatilisation of pesticides from fallow soil, Tech. Rep. 2, Environmental Planning Bureau series, DLO Winand Staring Centre, Wageningen, the Netherlands, 1997.

Smit, A. A. M. F. R., Leistra, M., and van den Berg, F.: Estimation method for the volatilisation of pesticides from plants, Tech. Rep. 2, Environmental Planning Bureau series, DLO Winand Staring Centre, Wageningen, the Netherlands, 99 pp., 1998.

Stafford, J. M., Wendler, G., and Curtis, J.: Temperature and precipitaion of Alaska: 50 year trend analysis, Theor. Appl. Clim., 67, 33-44, 2000.

Steinhäuser, K. G.: Environmental risks of chemicals and genetically modified organisms: A comparison, Environ. Sci. Poll. Res., 8, 120-126, 2001.

Stier, P., Feichter, J., Kinne, S., Kloster, S., Vignati, E., Wilson, J., Ganzeveld, L., Tegen, I., Werner, M., Schulz, M., Balkanski, Y., Boucher, O., Minikin, A., and Petzold, A.: The aerosolclimate model ECHAM5-HAM, Atmos. Chem. Phys., 5, 11251156, 2005.

Tanaka, M.: The onset and retreat dates of the austral summer monsoon over Indonesia, Australia, and New Guinea, J. Meteor. Soc. Japan, 72, 255-266, 1994.

UNECE: Protocol to the 1979 Convention on Long Range Transboundary Air Pollution on persistent organic pollutants and Executive Body decision 1998/2 on information to be submitted and the procedure for adding substances to Annexes I, II and III to the protocol on persistent organic pollutants, Document No. ECE/EB.AIR/60, United Nations, Geneva, 1998.
UNEP: Regionally Based Assessment of Persistent Toxic Substances, United Nations Environment Programme, Geneva, 2003.

UNEP-CEG: The development of science-based criteria and a procedure for identifying additional persistent organic pollutants as candidates for future international action, Draft proposal on procedures for identifying persistent organic pollutants for future international action, UNEP/POPS/INC/CEG/2/2, United Nations Environment Programme, Criteria Experts Group, Wien, Austria, 1999.

Vallack, H. W., Bakker, D. J., Brandt, I., Brorström-Lundén, E. A., Brouwer, A. B., Bull, K. R., Gough, K., Guardans, R., Holoubek, I., Jansson, B., Koch, R., Kuylenstierna, J., Lecloux, A., Mackay, D., McCutcheon, P., Mocarelli, P., and Taalman, R. D. F.: Controlling persistent organic pollutants - what next?, Environ. Toxicol. Pharamacol., 6, 143-175, 1998.

Wallace, J. and Hobbs, P.: Atmospheric Science. An Introductory survey, Academic Press, San Diego, 1977.

Wania, F. and Mackay, D.: A global distribution model for persistent organic chemicals, Sci. Tot. Environ., 160/161, 211-232, 1995.

Wania, F. and Mackay, D.: The evolution of mass balance models of persistent organic pollutant fate in the environment, Environ. Poll., 18, 223-240, 1999.

Webster, P. J., Magana, V. O., Palmer, T. N., Shukla, J., Tomas, R. T., Yanai, M., and Yasunari, T.: Monsoons: processces, predictability and the prospects of prediction, J. Geophys. Res., 103(C7), 14 451-14 510, 1998.

Yoder, J. A. and Kennelly, M. A.: Seasonal and ENSO variability in global ocean phytoplankton chlorophyll derived from 4 years of SeaWiFS measurements, Global Biogeochem. Cycles, 17, doi:10.1029/2002GB001 942, 2003. 